\title{
The impact of psychosocial need and needs resolution on quality of life in patients with brain tumors
}

\section{Terry Bunston, Ph.D., Deborah Mings, R.N., M.H.Sc., Normand Laperriere, M.D., Jacquey Malcolm, M.D., and Dorothy Williams, M.S.W.}

The Toronto Hospital/Princess Margaret Hospital, Toronto, Ontario, Canada; and Hamilton Regional Cancer Centre, Hamilton, Ontario, Canada

The diagnosis of cancer of the central nervous system (CNS) is often the diagnosis of an incurable, progressive disease with devastating effects on the physical, psychosocial, and cognitive functioning of patients. Because many of the treatment options are noncurative in nature, issues related to quality and quantity of life become paramount.

The purpose of the authors' research was to explore the prevalence of psychosocial needs in this cancer population and to determine whether these needs and their resolution impact on quality of life (QOL).

Telephone interviews were conducted with 75 patients in whom primary CNS cancer was diagnosed and who were able to pass the Mini-Mental Health Status Examination. Analysis of results indicated that the majority of patients (97.3\%) had at least one concern; concerns over treatment side effects, controlling uncertainty, having a meaningful existence, self and body image, and family concerns were among the five most frequently cited need domains. Most patients (91.8\%) received help. However, $75.3 \%$ reported needing additional help. The number of needs reported and the severity of fatigue most significantly impacted QOL.

The study identified the needs and experiences of the patient with CNS cancer. Quality of life and needs assessment information can be used to screen patients for distress and to measure the outcome of medical and psychosocial care and ultimately to ease the burden of illness.

Key Words * brain tumor * quality of life * psychosocial need

A diagnosis of cancer of the central nervous system (CNS) is the diagnosis of an often incurable, progressive disease. Patients with primary tumors of the CNS represent a heterogeneous group in which survival rates vary widely depending on the primary tumor type. Patients with low-grade gliomas have a median survival time of 5 years, whereas for patients with malignant gliomas, it is 1 year. The 5-year survival rate of patients with primary lymphoma of the brain is approximately $25 \%$ but is usually less than that for patients older than 60 years of age. Ependymomas and meningiomas are associated with significantly higher patient survival rates.[16] In many cases, this is an illness marked by a steady 
decline, punctuated by periodic crisis, toward death. Like those with progressive neurodegenerative diseases, individuals with cancers of the CNS have to cope with cognitive impairment, compromised performance status, neurological deterioration, impaired communication, and personality change. These patients share with other cancer patients the experiences of surgery, radio- and chemotherapy.

Care for these patients may include a mix of treatment for cure, for life prolongation, rehabilitative treatment, and palliative care in varying proportions. Therapeutic interactions, when cure is not promising, are aimed at allowing a patient to live meaningfully for as long as possible. As brain tumor patients "struggle to relate to their environment"[21] and cope with the many devastating changes brought on by this disease, quality of life (QOL) becomes an important concern for them.

To alleviate the burdens created by this life-threatening illness, it is critical to have information on patients' and families' needs and QOL. The care that patients with cancer of the CNS require includes addressing the psychosocial consequences of the disease. Although we know that psychosocial care can be effective, $[15,21,25,57,62,63]$ without data on needs and QOL, effective interventions are difficult to design and evaluate. Psychosocial data are particularly useful as an outcome of care. In direct application to medical practice, the impact of symptoms and treatment options on QOL can aid in the decision-making process for patients, families, and healthcare providers. As well, QOL is a vital quality assurance issue in measuring the toxic effects on the target organ.[13]

The purpose of our research is to explore the impact of the burden of psychosocial need on QOL. Specifically, this paper will address two research questions. First, what is the prevalence of psychosocial needs in this population of cancer patients and what are the most prominent needs? Second, do psychosocial needs and problems in resolving need impact on QOL and, if so, what is the path of their influence on QOL?

\section{REVIEW OF THE LITERATURE}

It is well documented in the literature that CNS cancer patients suffer from short-term memory loss, declining strength, fatigue, loss of hearing and eyesight, seizures, cognitive deficits, altered facial appearance, motor alterations, and changes in speech.[2,5-8,10,11,20,21,24,39,43-45,51,61] These changes are associated with psychological and social distress that includes anxiety, depression, guilt, uncertainty, difficult interpersonal relationships, social isolation, loss of control, loss of independence, and negative affect.[2,4,8,11,20,23,31,40,43,45,51,60-62] These patients live a "double existence;" they must simultaneously cope with their concerns about dying and their concerns about how long they can continue to maintain function.[43] Many of the studies that examine the psychosocial consequences of CNS are not empirically based. There is a rich clinical literature that describes the deleterious impact of this disease on patients and families, often providing practical guidelines or describing psychosocial interventions.[2,5-8,11,20,21,26,35,36,43,45,49,53,58]

The empirically based psychosocial literature on CNS cancers center on performance status and survival as indicators of QOL[1,3,22,27,28,32,33,38,41,44,46,52,54,64] Performance status is most often assessed using the Karnofsky Performance Scale (KPS) and cognitive functioning as indicators of QOL, which are proxies that view QOL from a single perspective. There is, however, consensus that QOL is a multidimensional concept that is best measured from the patient's perspective. In fact, the few available studies that have examined the association between the KPS and QOL have found a lack of correspondence between the two.[41,47] 
Only a few investigators have addressed subjective QOL either as a multidimensional concept or as a component of the broader concept.[30,41,42,47,48,55,59-61,66,67] Aiken[1] has stated in his review of QOL in malignant astrocytic cancers that "despite two decades of modern organized clinical trials for the treatment of malignant glioma, there is scant literature about the QOL of these patients." Two QOL questionnaires have been developed specifically for the brain tumor population that have been shown to be valid and reliable.[47,67] Both of these measures have modules attached to existing well-known QOL measures. Osoba and colleagues[47] have developed a brain tumor module to accompany the Europoean Organization for Research and Treatment of Cancer QOL questionnaire and Weitzner and colleagues[67] have similarly developed a module to accompany the Functional Assessment of Cancer Therapy (FACT). Other measures of QOL developed specifically for brain tumor patients such as the PRESTON Profile,[40] the Aachen Life Quality Inventory,[30] and a questionnaire developed by Mackworth, Fobair, and Prados[41] have not been subjected to rigorous testing.

Although QOL has been described using a number of parameters, only two studies, to our knowledge, have used standardized QOL questionnaires that have been sufficiently evaluated. Weitzner and colleagues, [66] using the FACT, found that QOL was most affected by the extent of tumor involvement, bilateral involvement, poor performance status, aggressive treatment, by being female, divorced, and by an inability to work. Osoba and colleagues,[48] using the Europoean Organization for Research and Treatment of Cancer QOL questionnaire, documented that recurrence, dysphasia, confusion, and motor deficit had detrimental effects on QOL and that although all were associated with decreased physical functioning, they otherwise differentially impacted on the specific dimensions of QOL. For example, confusion was associated with decreases in role-cognitive function, whereas dysphasia was associated with decreases in role and social functioning.

Other studies based their evaluations of QOL on a component of QOL such as activities of daily living (ADL)[14] or mood states.[46,61] For example, Coucair and colleagues[14] identified that ADL were associated with gender, performance status, mental status, speech impairment, motor deficit, cranial nerve deficit, and corticosteroid usage. Mackworth, et al.,[41] examined factors affecting QOL by using the well-being subscale of their own instrument as the dependent variable, regressing it on the other dimensions of the instrument. Including both children and adults, they discovered that depression and socializing had the largest impact on well-being whereas energy and reduced symptoms had less of an effect.

Another perspective on QOL has been to use a more qualitative approach. Taphoorn and colleagues[59,61] based their assessment of QOL on established mood scales and a structured interview. In a study that compared patients with a low-grade glioma and survivors of the disease, they documented that patients reported more disturbances in affective status, had more complaints about their physical condition, and were less satisfied with their overall sense of well-being.

Both the clinical and research literature illustrates the detrimental effects of CNS cancer on components of QOL. Only a few investigators have introduced standardized measures that represent a multidimensional and subjective perspective of QOL. Similarly, we were unable to find any reported literature that explicitly assessed patients' concerns and needs. Because the psychosocial aspects of CNS cancers are just beginning to be explored, there is much to learn about the QOL of these patients, as well as the need to apply this knowledge to clinical practice.

\section{CLINICAL MATERIAL AND METHODS}




\section{Design and Study Population}

Because an objective of the research was to verify the reliability and validity of an inventory of patients' psychosocial needs, the design was a cross-sectional one in which data were collected at two points, 1 week apart. The study population consisted of outpatients at the Princess Margaret Hospital in Toronto, Ontario, Canada, in whom a primary brain tumor had been diagnosed. Inclusion criteria were 1) age of 18 years and older, 2) ability to understand and speak English, and 3) ability to provide informed written consent. Exclusion criteria were 1) hearing problems, 2) first visit to the clinic, or 3) cognitive impairment. Cognitive impairment was assessed using the Mini-Mental Health Status Examination, and patients who scored below 25 were excluded from the study. Physicians and nurses in the clinic identified appropriate patients to approach.

Patients who met the entry criteria were enrolled between July 1996 and April 1998 and they were given verbal and written explanations prior to signing a consent form. Data were collected by means of a telephone interview that took approximately 45 minutes to complete. The number of patients who were interviewed at both time points was 75 . Of the 95 eligible patients originally accrued, 15 patients dropped out of the study before the first interview. Of the remaining 80 patients, five were interviewed at Time 1 only. Of the 20 patients who either dropped out or completed Time 1 only, $45 \%$ (nine patients) were too ill to be interviewed, $25 \%$ (five patients) could not be contacted by telephone, $5 \%$ (one patient) refused to complete Time 2 , and $25 \%$ (five patients) had other reasons.

\section{Measurement Instruments}

The questionnaire package consisted of five instruments and a section on demographics. The Coping in Stressful Situations scale is designed to measure three major types of coping styles: task-oriented, emotion-oriented, and avoidance coping. The Coping in Stressful Situations scale is a 48-item inventory in which individuals are asked to indicate how much they engage in specific activities, representing these three coping strategies, when they encounter a difficult or stressful situation.[17,50] Functional Assessment of Cancer Therapy with the brain tumor module is designed to measure QOL in patients with cancer.[12,67] This measure consists of the following subscales: physical, functional, social/family, and emotional well-being and relationship with doctor as well as the total score of these subscales. The relationship with doctor subscale was not used for this study because of the lack of variance in the responses to the two items that comprise this subscale.

The Fatigue Severity Scale is a nine item scale that measures the degree to which individuals with chronic conditions, including cancer, experience fatigue.[34] The Life Event Survey is designed to measure life event stress by assessing both the extent to which an event is desirable and the degree of personal impact.[56] Individuals are asked to identify events that occurred in the last 6 months and indicate the extent to which the event had a negative or positive impact on their lives.

The Princess Margaret Hospital Needs Assessment Inventory, developed by two of the investigators, is designed to identify psychosocial needs, difficulty resolving need, availability and sources of support, the need for help, barriers to need resolution, and service preferences. A qualitative methodology was used to identify a total of 58 specific needs that were then grouped into 12 domains of need: healthcare system, treatment side effects, maintenance of ADL, controlling uncertainty, self and body image, nutrition, finances and employment, family, belonging, social support, emotional distress, and meaningful existence. Standard psychometric procedures were used to test for validity and reliability. All of the instruments have established reliability and validity. 


\section{CONCEPTUAL MODEL OF THE DETERMINANTS OF QOL}

Using the literature and clinical experience as the basis for the hypothesized model, the following hypotheses are brought forward to clarify the paths of the determinants of global QOL (that is, the total score on the FACT). A diagram of the hypothesized model is shown in Fig. 1, depicting how the independent variables interact with one another and their paths of influence on QOL. For simplicity and clarity, the factors thought to influence QOL have been grouped as follows: demographic and medical characteristics, problems resolving need, burden of need, availability of resources, fatigue, and life event stress. Problems resolving need include coping strategies used to problem solve, difficulty resolving need, and number of barriers to needs resolution. Burden of need refers to number of needs and number of domains in which an individual requires assistance.

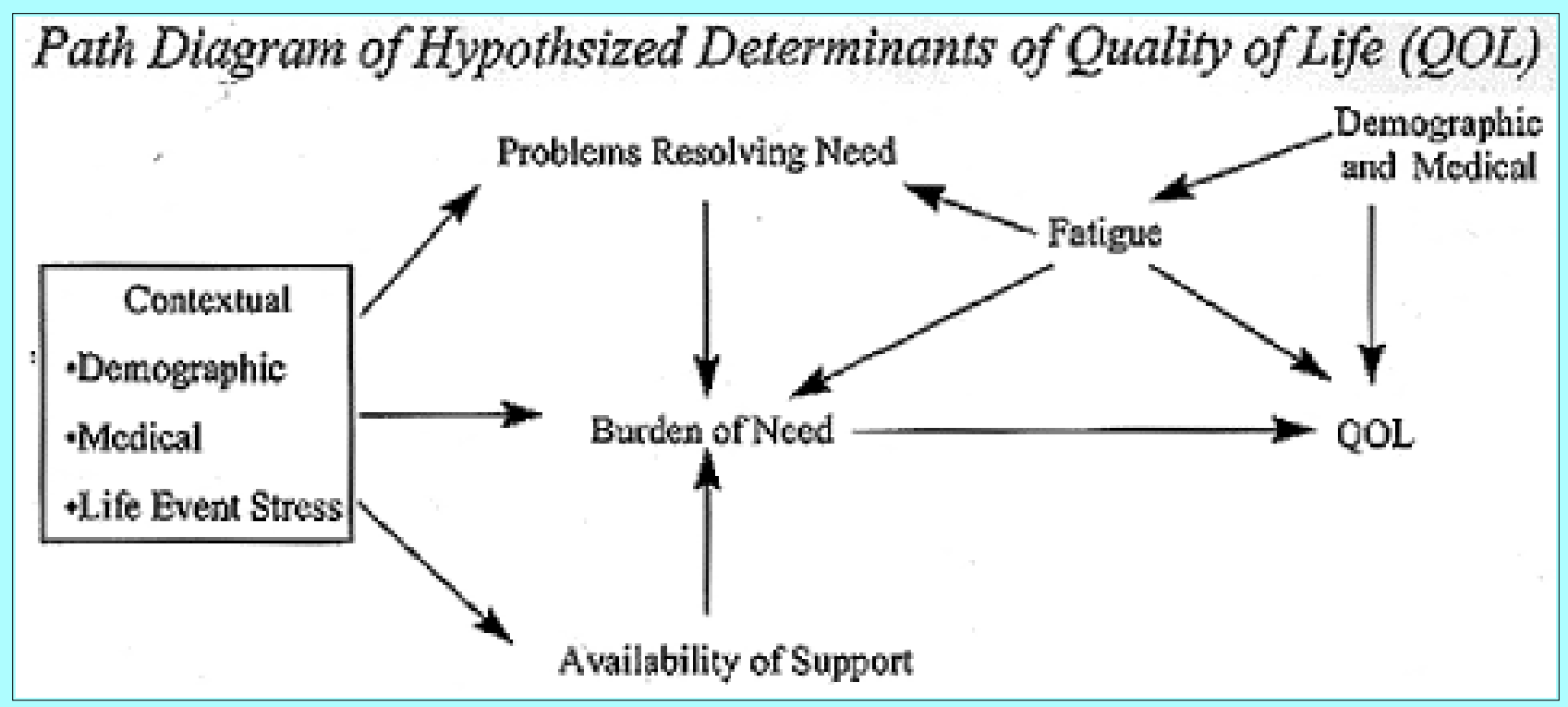

Fig. 1. Diagram illustrating interaction of independent variables and the paths of influence on QOL.

Demographic variables and life event stress are hypothesized to be contextual factors that have an indirect impact on QOL. Their influence is felt through their relationships with problems resolving need, availability of resources, and fatigue. For example, income can be seen as a means to acquire the resources necessary to decrease the burden of need and thus increase QOL. Marital status and being a member of a family unit are expected to impact on availability of support by providing the necessary help.

This disease and its side effects are believed to have both a direct and indirect impact on QOL. Indirectly, the severity of the disease will impact on fatigue, problems resolving need, and burden of need. As the disease progresses, the patient is likely to suffer more fatigue and encounter more difficulties coping that will generate a greater number of needs. Severity of disease will also have a direct effect on QOL, particularly on physical and functional well-being, which are dimensions of QOL.

Fatigue is hypothesized to have a "cloud effect." That is, as fatigue increases, an individual will have more problems resolving need, a greater burden of need, and experience a lower QOL. Studies in the literature document a substantial relationship between fatigue and QOL.[9,19,29,65] Experiencing problems resolving need is hypothesized as impacting on the burden of need and the availability of support. The more dependence on emotion-oriented and avoidance coping strategies, the greater the 
burden of need. However, the greater the use of task-oriented strategies, the less the burden of need. The more difficulties coping and barriers to needs resolution encountered by the patient, the greater the burden of need. Burden of need is hypothesized to have a direct relationship to QOL: the more needs a patient has, the lower the QOL. Last, the provision of support is hypothesized to reduce the number of needs by supplying the resources necessary to meet these needs.

\section{RESULTS}

\section{Demographic and Medical Characteristics}

As noted in Table 1, the average age of the patients was 43.6 years (range 22-76 years), there were slightly more women than men, most patients were married, and slightly more that $77.3 \%$ had been born in Canada. Although one-third of the patients were currently employed, slightly more than half were either on sick leave or long-term disability. This was a highly educated population; one-third of the patients had an university degree.

\begin{tabular}{|c|c|c|}
\hline $\begin{array}{c}\text { TABLE } 1 \\
\text { SUMMARY OF DEMOGRAPHK AND MED CAL CHARAC }\end{array}$ & RISTKS IN & 5 PATIENTS* \\
\hline Characteristic & $\begin{array}{c}\text { No. of } \\
\text { of Patients }\end{array}$ & Percentage \\
\hline age (urs) mean $43.6 \mathrm{SD} 12.3$ range $22-76$ & & \\
\hline $\operatorname{sen} x$ & & \\
\hline $\mathrm{F}$ & 40 & 53.3 \\
\hline M & 35 & 46.7 \\
\hline marrieddiving w/partner & 55 & 73.3 \\
\hline li wing arrangem ents & & \\
\hline spouse/partner & 20 & 26.7 \\
\hline spouse/partner \& children & 30 & 40 \\
\hline other nudear iextended family & 21 & 28 \\
\hline friend & 1 & 1.3 \\
\hline alone & 3 & 4 \\
\hline ages of children (yrs) & & \\
\hline children $\times 18$ & 32 & 42.7 \\
\hline children > 19 & 19 & $\begin{array}{l}25.3 \\
32\end{array}$ \\
\hline born in Canada & & \\
\hline yes & 58 & 77.3 \\
\hline education & & \\
\hline no diploma & 11 & 14.7 \\
\hline high school di ploma & 11 & 14.7 \\
\hline some uni iersitybom plete com munity college & 28 & 37.3 \\
\hline uni versity/postgraduate degree & 25 & 33.3 \\
\hline employment status & & \\
\hline paid employment & 26 & 34.7 \\
\hline homemaker & 8 & 10.7 \\
\hline sick leave & 14 & 18.7 \\
\hline long-term disability leave & 27 & 31 \\
\hline income (69 patients) & & \\
\hline $\begin{array}{l}\times 29,999 \\
30000-49,999\end{array}$ & $\begin{array}{l}16 \\
13\end{array}$ & 23.2 \\
\hline $50,000-79,999$ & 14 & 20.3 \\
\hline $80,000-99,999$ & 14 & 20.3 \\
\hline$\unrhd 100,000$ & 12 & 17.4 \\
\hline tumor type (74 patients) & & \\
\hline astrocytoma & 25 & 33.8 \\
\hline glioblastoma & 14 & 18.9 \\
\hline oligodendroglioma & 10 & 13.5 \\
\hline medullo blastoma. & 5 & 6.8 \\
\hline
\end{tabular}




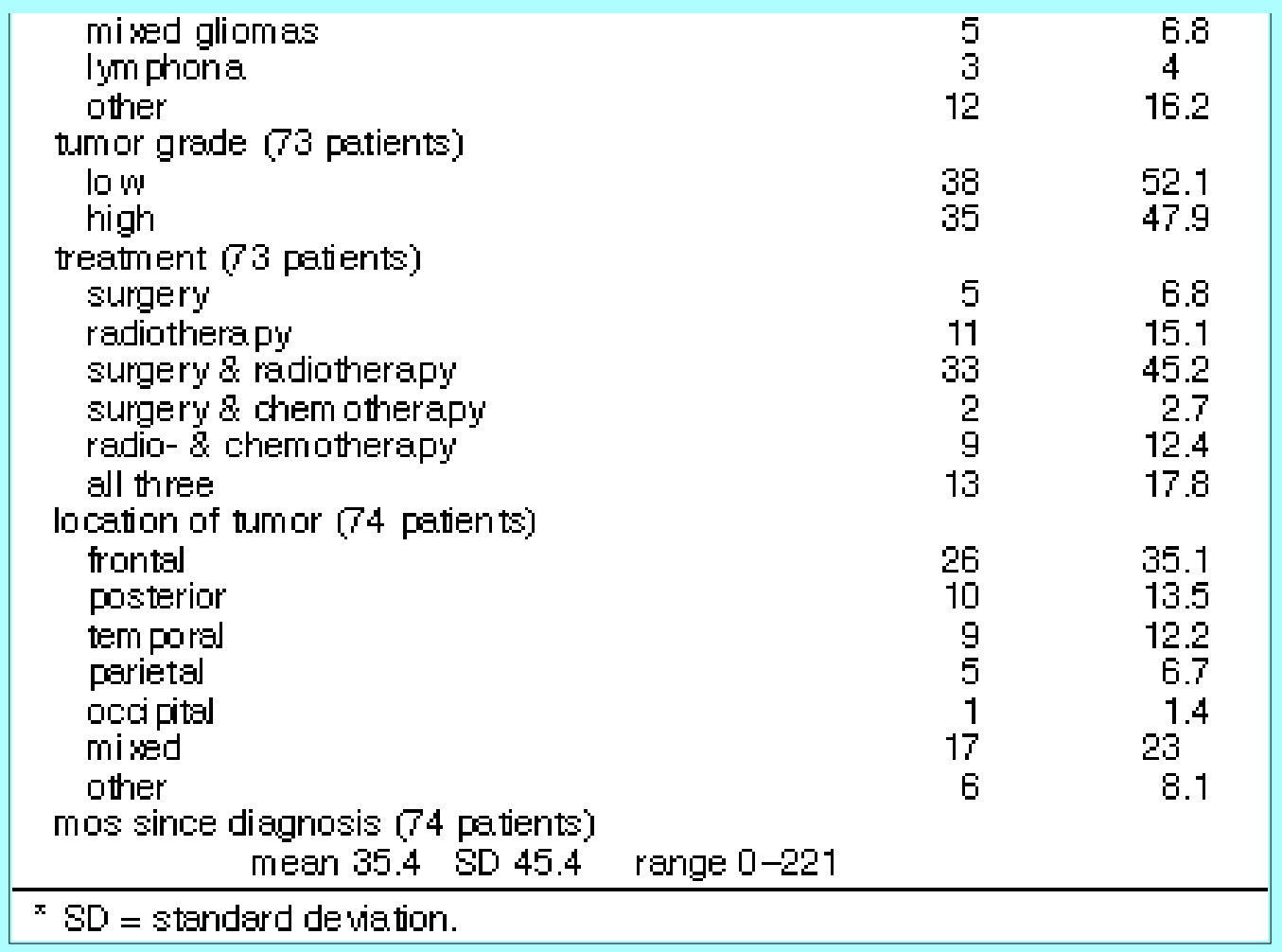

On average, the length of time since diagnosis was 35.4 months. As shown in Table 1, astrocytoma was the most common tumor type, followed by glioblastoma and oligodendroglioma. Tumors were graded as either of low or high severity by one the investigators (J.M.); patients were almost evenly divided between the two grades.

\section{Psychosocial Needs}

It was the exceptional patient who was without concerns or needs: $97.3 \%$ of patients reported at least one concern (Table 2). The average number of needs was 22.4 out of a possible 58 . When grouped into the 12 domains, the average number of domains was 7.2; on average patients had needs in more than half of the domains. Treatment side effects, controlling uncertainty, and meaningful existence were cited by at least three-quarters of the patients as a need (Table 2). Controlling uncertainty refers to concerns about how the cancer could impact on the future, recurrence, and death, as well as the patient's current concerns about reacting to the cancer. Meaningful existence refers to concerns over living one's life fully and taking advantage of experiences that could contribute to a meaningful existence. Other domains cited by at least $50 \%$ of the study participants included self and body image, family concerns, financial concerns, emotional distress, and maintenance of everyday activities. There was no domain that was cited by less than one-third of the patients. Although most patients with needs were getting help (67 [91.8\%] of 73) and evaluated that help as positive, $75.3 \%$ of the patients indicated that they required help or desired additional help to meet their needs. 


\begin{tabular}{|c|c|c|}
\hline \multicolumn{3}{|c|}{$\begin{array}{l}\text { TABLE } 2 \\
\text { SUMMAY OF PSVCHOSOC AL NEEDS IN PATIENTS WITH CNS CANCER }\end{array}$} \\
\hline Characteristic & $\begin{array}{l}\text { No. of } \\
\text { Patierts }\end{array}$ & $\%$ \\
\hline \multicolumn{3}{|l|}{ patients } \\
\hline wheeds & 73 of 75 & 97.3 \\
\hline recei wing help & 67 of 73 & 91.8 \\
\hline needing additional help & 55 of 73 & 75.3 \\
\hline mean no. of needs & 22.4 of 58 & \\
\hline mean no. of need domains & 7.2 of 12 & \\
\hline \multicolumn{3}{|l|}{ need domains } \\
\hline heal thcare system & 40 & 53.3 \\
\hline treatment side effects & 63 & 84 \\
\hline maintenance of everyday activites & 41 & 54.7 \\
\hline controlling uncertainty & 62 & 82.7 \\
\hline self and bod yimage & 50 & 66.7 \\
\hline nutrition & 35 & 46.7 \\
\hline financesiem ploym ent & 45 & 60 \\
\hline family & 47 & 62.7 \\
\hline belonging & 27 & 36 \\
\hline social support & 31 & 41.3 \\
\hline emotional distress & 44 & 58.7 \\
\hline meaningful existence & 55 & 73.3 \\
\hline
\end{tabular}

\section{Relationship Between Psychosocial Needs and QOL}

The mean scores for the FACT-Brain subscales and the total score indicate that these patients had a moderate QOL. Scores ranged between 2.8 for functional well-being to 3.2 for social/family well-being on a scale where 0 indicates a poor QOL and 4 indicates a high QOL.

In accord with the hypothesized relationships between the variables and QOL, QOL was significantly correlated with many of the hypothesized factors (Table 3). A notable exception was the demographic characteristics of the patients; none were correlated to QOL. Similarly, with the exception of months from diagnosis, none of the medical variables were related to QOL. As the patient's experience with cancer lengthened, QOL declined. 


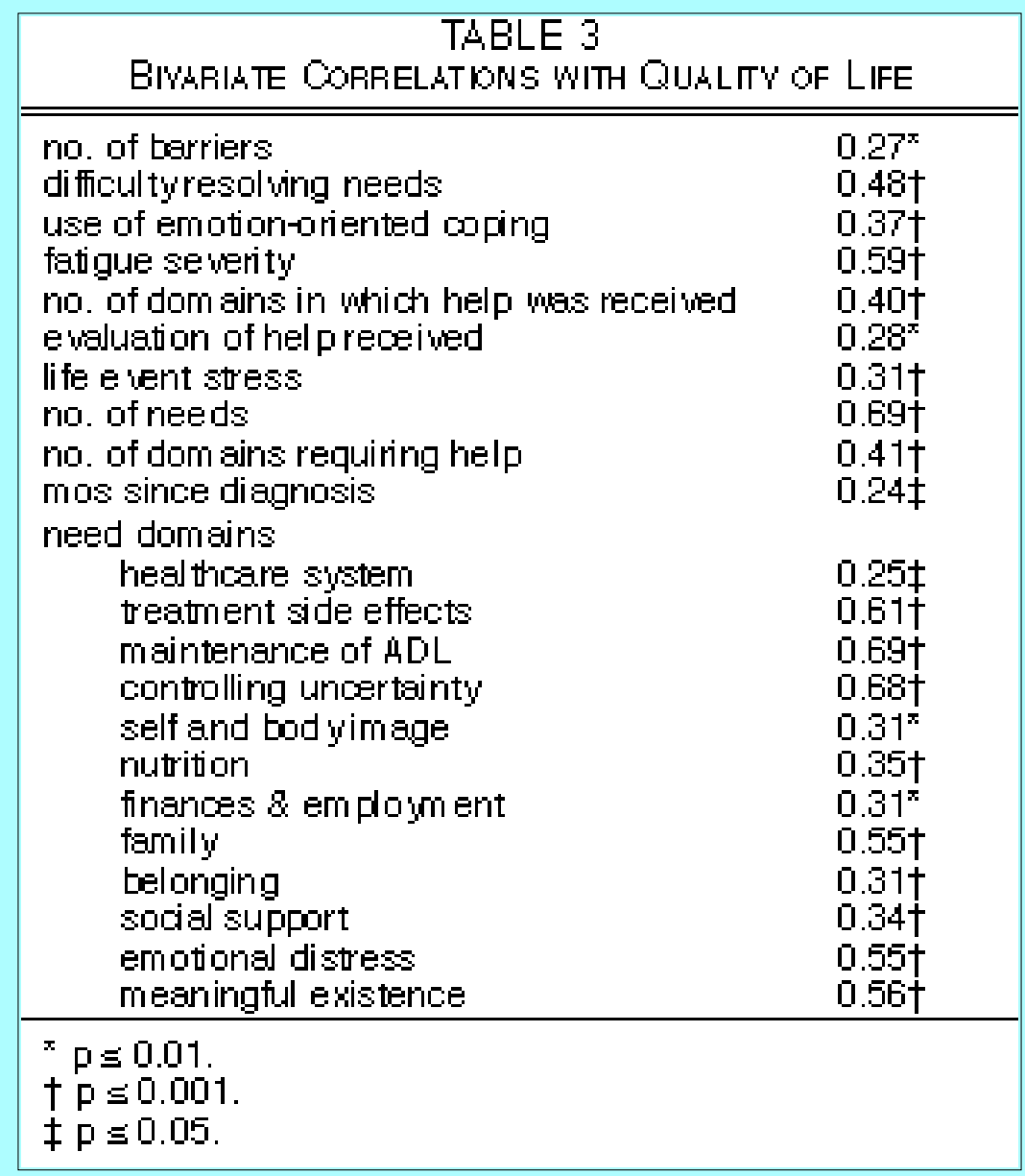

It is evident from the correlations that psychosocial needs and problems resolving those needs had substantial impact on QOL. The total number of needs as well as needs in the domains of maintenance of everyday activities, controlling uncertainty, treatment side effects, meaningful existence, and family concerns were all strongly correlated to QOL in the predicted direction: the greater the number of needs, the lower the QOL. All of the other need domains had statistically significant relationships to QOL that were moderately to somewhat weak in the same direction: the healthcare system, self and body image, nutrition, finances and employment, belonging, and social support.

Of those factors reflecting coping strategies and difficulties resolving need, difficulty resolving needs and number of domains in which help or more help was required were correlated with QOL at a moderate level. The more difficulty a patient had resolving needs and the greater the number of domains in which help was required beyond that already provided, the lower the QOL. Only the use of emotion-oriented coping strategies was correlated to QOL; the more a patient used these strategies as compared to the use of task-oriented or avoidance strategies, the lower the QOL. Number of barriers to needs resolution was also correlated to QOL, although this was a moderately weak correlation. The greater the number of barriers, the lower the QOL. Both the presence and absence of support were correlated to QOL in the expected direction, with equivalent moderate correlations. The evaluation of support, however, had a moderately weak correlation to QOL. The presence and positive appraisal of support was positively associated with QOL; the more help available and the more positive its evaluation, the higher the QOL. The greater the number of domains in which help was required, the lower the QOL.

In addition to needs assessment and demographic/medical factors, life event stress and fatigue were also examined as possible correlates of QOL. Fatigue had a strong correlation to QOL; the more severe the fatigue reported by a patient, the lower the QOL. Life event stress, an indicator of the context in which 
the patient experiences cancer, had a weaker association with QOL; the more negatively life event stress in the past 6 months was evaluated, the lower the QOL.

\section{Determinants of $Q O L$}

Although the bivariate correlations identify those factors associated with QOL, simple bivariate correlations fail to take into account the relative impact of these variables on QOL. By using multiple regression techniques, the relative impact of these variables can be calculated, the resulting model can be compared with the hypothesized model, and a model can be developed to trace the paths of those variables that impact on QOL either directly or indirectly.

The following empirical model was formulated on the basis of theoretical considerations, which are particularly important in the absence of a longitudinal design. Variables were excluded for any of the following reasons: 1) the bivariate correlations with the dependent variable were not significant at a probability level of less than $0.05,2$ ) multicollinearity between the independent variables, 3) the required assumptions of normal variance and linearity were not met, or 4) a variable lost its explanatory power in the multiple regression analysis.

As shown in Table 4 and the path diagram in Fig. 2, QOL was directly influenced by only two variables: fatigue and number of needs. Taking into account the indirect effects, fatigue was as influential as number of needs in its impact on QOL. Indirectly, fatigue was influential through its impact on number of needs, number of domains in which a patient received support, and emotion-oriented coping. The more severe the fatigue, the greater the number of needs and the fewer the number of domains in which support was received. At the next level of influence--help received--coping difficulties and barriers to needs resolution were influential through their impact on number of needs. The less help received, the more difficulty coping with needs and the greater the number of barriers, the more needs reported by the patient.

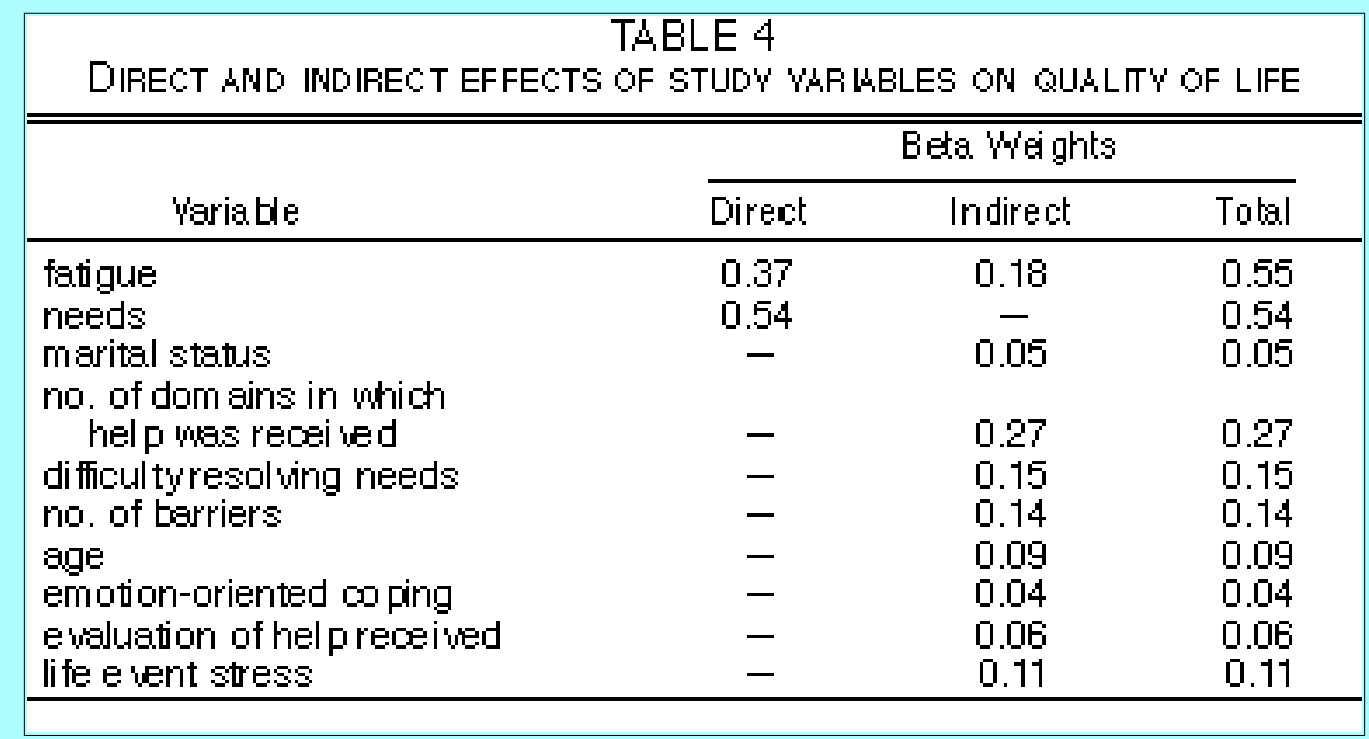




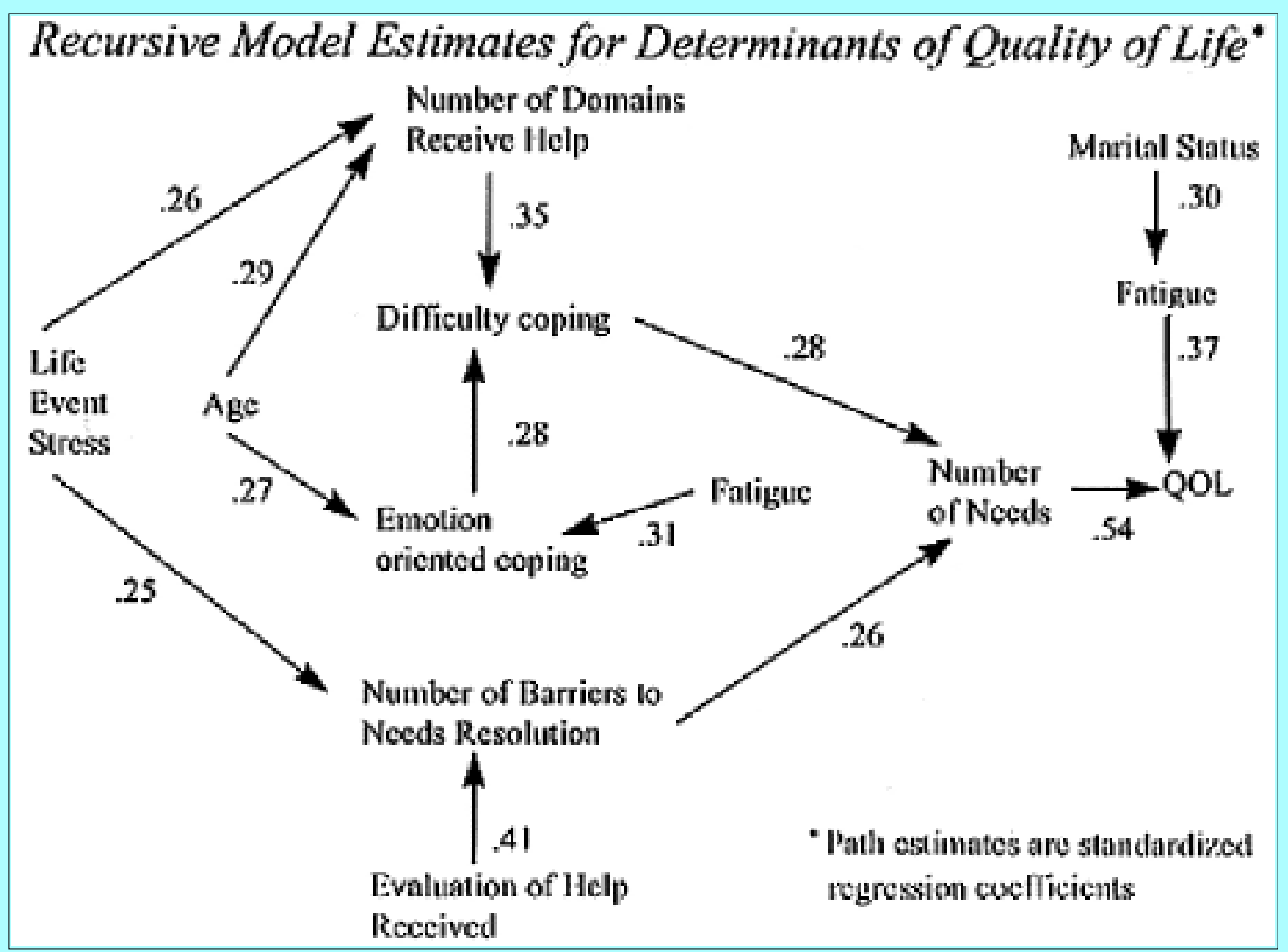

Fig. 2. Diagram showing the relationship of variables to QOL, which was directly affected by only fatigue and number of needs.

Each of these factors was in turn influenced by a series of variables. These variables, however, because of their greater distance from QOL, had substantially less impact. Age was both correlated to number of domains in which help was received and emotion-oriented coping. Younger patients had more domains in which they received help and were more likely to use emotion-oriented coping strategies than older patients. Emotion-oriented coping was also influenced by fatigue and number of children. However, the total effect of age of children was $p<0.05$ and thus excluded from the model.

Number of barriers to needs resolution was influenced by the strength of ethnic ties, income, and evaluation of help received. Neither strength of ethnic ties nor income had sufficient impact on QOL to remain in the model. However, the stronger the tie to an ethnic group, the greater the number of reported barriers, and the higher the income, the fewer the number of reported barriers. The evaluation of help received to meet needs was of sufficient strength to remain in the model. Patients who rated the help they received as positive were more likely to indicate that they had experienced fewer barriers to needs resolution.

Lastly, life event stress was a determinant of both the number of domains in which help was received as well as barriers to needs resolution. Life event stress presents interesting results. The more negative the stress of life events was perceived to be, the fewer the barriers to needs resolution. On the other hand, the more negative the appraisal of life event stress, the less help received to meet needs.

\section{DISCUSSION}

In summary, with two exceptions, all of the study participants had psychosocial needs (an average of 
22.4 out of a possible 58 needs). There was no need domain in which fewer than one-third of the patients reported having needs. The most frequently cited needs were treatment side effects, controlling uncertainty, and meaningful existence. Although a majority of patients were receiving help, $75.3 \%$ indicated that they required additional help. Likewise, $54.7 \%$ of the patients indicated that they had at least one barrier to needs resolution.

Quality of life was significantly correlated to a number of factors. However, demographic and medical characteristics were not often correlated to QOL. This lack of correlation is substantiated in the literature. Weitzner and colleagues[66] found that the FACT scores correlated only to gender, marital status, inability to work, and extent of tumor involvement. Giovagnoli, et al.,[23] documented the lack of correlation of demographic variables and tumor involvement to QOL using the Functional Living Index--Cancer. Similarly, Mackworth, et al.,[41] found a lack of correlation between age and QOL. Although age is usually considered to be an important prognostic factor in surviving a brain tumor,[37] it is not a predictor of QOL.

When multiple regression techniques were applied, fatigue and number of needs were the only significant predictors of QOL with an $\mathrm{r}$ of 0.77 and an $\mathrm{r}^{2}$ of 0.59 . Because fatigue had substantial indirect effects, its impact on QOL was equal to that of the extent of psychosocial need. At the next level of influence, help received, difficulty coping with needs, and barriers to needs resolution had a moderate effect on QOL. The factors of importance focus on burden of need, fatigue, availability of resources, and difficulties coping. Demographic and medical characteristics play an insignificant role in influencing QOL.

When compared with the hypothesized model, the empirical model differed little from the conceptual model. In both, fatigue and burden of need were direct determinants of QOL. However, whereas medical characteristics, specifically grade of tumor, were hypothesized to be direct determinants of QOL, this did not prove to be the case in the empirical model. In addition, the hypothesis concerning the relationship of the demographic variables to the variables in the model was not borne out.

A limitation of the study is the overemphasis on patients whose cancer is not sufficiently advanced to preclude participation in the study. This would likely impact on severity of disease. Although the grade of the tumor was evenly distributed between high- and low-grade tumors, patients with serious cognitive impairment were excluded from the study. The focus of this research was on 1) the identification and magnitude of psychosocial needs, 2) the resolution of need, 3) the role fatigue plays in determining the level of need and difficulties in resolving need, and 4) the impact of these factors on QOL. This meant that a number of factors known to be determinants of QOL have not been included in this study. These include, for example, symptom severity, optimism, and locus of control.

In a population where cure or long-term remission are so often elusive, QOL becomes a major focus of care. It is important to know the patient's experience of illness, the burden, changes in lifestyle and perspective, and the positive and the negative variables. We can know this best by asking patients to tell us about their needs and QOL. As Lesley Fallowfield said, "imagining what one's quality of life might be in different states is not the same as experiencing the state."[18]

\section{CONCLUSIONS}

When needs and QOL assessment are integrated into the care of patients, QOL also becomes a goal of care. No longer is the primary focus on survival alone. Psychosocial care can be effective in helping 
patients cope with the diagnosis and treatment of cancer. However, research on the needs and QOL of brain tumor patients is essential to the psychosocial care of patients, and psychosocial care is essential to the well-being of these patients. With needs assessment data, specific needs of patients can be pinpointed for intervention. In our study, treatment side effects, controlling uncertainty and meaningful existence were cited by patients as areas of need requiring intervention. Quality of life can be used as both a source of information for health care providers and as an outcome measure of medical and psychosocial care. Maintaining QOL requires a balance between the burden of illness and making resources accessible to patients to help them reduce that burden.

\section{References}

1. Aiken RD: Quality-of-life issues in patients with malignant gliomas. Semin Oncol 21:273-275, 1994

2. Amato CA: Malignant glioma: coping with a devastating illness. J Neurosci Nurs 23:20-22, 1991

3. Ammirati M, Vick N, Liao YL, et al: Effect of the extent of surgical resection on survival and quality of life in patients with supratentorial glioblastomas and anaplastic astrocytomas. Neurosurgery

21:201-206, 1987

4. Awwad S, Cull A, Gregor A: Long-term survival in adult hemispheric glioma: prognostic factors and quality of outcome. Clin Oncol 2:343-346, 1990

5. Barker E: Brain tumor. Frightening diagnosis, nursing challenge. RN 53:46-52, 1990

6. Baumann CK, Zumwalt CB: Intracranial neoplasms. An overview. AORN J

50:240,242,244-248,250-251,253,256-257, 1989

7. Borozny M, Gray E, Ratel M: Nursing concerns associated with radical skull base surgery: a case study. J Neurosci Nurs 25:45-51, 1993

8. Burgess KE: Neurological disturbance in the patient with an intracranial neoplasm: sources and implications for nursing care. J Neurosci Nurs 15:237-242, 1983

9. Camarillo MA: The oncology patient's experience of fatigue, in Whedon M (ed): Qual Life 1:39-44, 1992

10. Campbell C: Acoustic neuroma: nursing implications related to surgical management. J Neurosci Nurs 23:50-56, 1991

11. Carr SH: Adaptation to loss: occupational therapy as a way of life. Am J Occup Ther 45:167-170, 1991

12. Cella DF: F.A.C.T. Manual. Functional Assessment of Cancer Therapy (FACT) Scales and the Functional Assessment of HIV Infection (FAHI) Scale and the Functional Assessment of Multiple Sclerosis (FAMS) Scale, ed 3. Chicago: Rush-Presbyterian-St.Luke's Medical Center, 1996

13. Choucair AK: Proposals for evaluation of toxic effects associated with treatment of gliomas: a call for action. J Natl Cancer Inst 82:531-532, 1990

14. Choucair AK, Scott C, Urtasun R, et al: Quality of life and neuropsychological evaluation for patients with malignant astrocytomas: RTOG 91-14. Int J of Radiat Oncol Biol Phys 38:9-20, 1997 
15. Cunningham AJ: From neglect to support to coping: the evolution of psychosocial intervention for cancer patients, in Cooper CL (ed): Stress and Breast Cancer. New York: Wiley, 1988, pp 135-153

16. Dollinger M, Rosenbaum EH, Cable G: Everyone's Guide to Cancer Therapy. Toronto: Somerville House Publishing, 1992

17. Endler NS, Parker JDA: Coping Inventory for Stressful Situations (CISS): Manual. Toronto: Multi-Health Systems, 1990

18. Fallowfield L: The Quality of Life. The Missing Measurement in Health Care. London: Souvenir Press, 1990

19. Ferrell BR, Grant M, Dean GE, et al: "Bone tired": the experience of fatigue and its impact on quality of life. Oncol Nurs Forum 23:1539-1547, 1996

20. Fisk JL, Del Dotto JE: Neuropsychological sequelae of brain tumors. Henry Ford Hosp Med J 38:213-218, 1990

21. Gardner R: Psychological care of neuro-oncology patients and their families. Br J Nurs 1:553-556, 1992

22. Giovagnoli AR, Boiardi A: Cognitive impairment and quality of life in long-term survivors of malignant brain tumors. Ital J Neurol Sci 15:481-488, 1994

23. Giovagnoli AR, Tamburini M, Boiardi A: Quality of life in brain tumor patients. J Neurooncol 30:71-80, 1996

24. Glasvassevich M, Thomas S, Galloway SC: Informational needs of patients who undergo excision of an acoustic neuroma. Axone 11:17-19, 1989

25. Greer S: Psycho-oncology: its aims, achievements and future tasks. Psychooncology 3:87-101, 1994 26. Hildebrand J, Gangji D: Supportive care of neurologic complications. Curr Opin Oncol 4:632-641, 1992

27. Hochberg FH, Linggood R, Wolfson L, et al: Quality and duration of survival in glioblastoma multiforme. Combined surgical, radiation, and lomustine therapy. JAMA 241:1016-1018, 1979

28. Hochberg FH, Slotnick B: Neuropsychologic impairment in astrocytoma survivors. Neurology 30:172-177, 1980

29. Hürny C, Bernhard J, Joss R, et al: "Fatigue and malaise" as a quality-of-life indicator in small-cell lung cancer patients. Support Care Cancer 1:316-320, 1993

30. Hütter BO, Spetzger U, Bertalanffy H, et al: Cognition and quality of life in patients after transcallosal microsurgery for midline tumors. J Neurosurg Sci 41:123-129, 1997

31. Irle E, Peper M, Wowra B, et al: Mood changes after surgery for tumors of the cerebral cortex. Arch Neurol 51:164-174, 1994

32. Keim H, Potthoff PC, Schmidt K, et al: Survival and quality of life after continuous accelerated radiotherapy of glioblastomas. Radiother Oncol 9:21-26, 1987 
33. Kleinberg L, Wallner K, Malkin MG: Good performance status of long-term disease-free survivors of intracranial gliomas. Int J Radiat Oncol Biol Phys 26:129-133, 1993

34. Krupp LB, LaRocca NG, Muir-Nash J, et al: The Fatigue Severity Scale. Application to patients with multiple sclerosis and systemic lupus erythematosus. Arch Neurol 46:1121-1123, 1989

35. Leavitt MB, Lamb SA, Voss BS: Brain tumor support group: content themes and mechanisms of support. Oncol Nurs Forum 23:1247-1256, 1996

36. Lehman LB: A difficult promise. Postgrad Med 93:43-44, 1993

37. Levin VA, Gutin PH, Leibel S: Neoplasms of the central nervous system, in DeVita VT Jr, Hellman S, Rosenberg SA (eds): Cancer: Principles and Practice of Oncology, ed 4. Philadelphia: JB Lippincott, 1993, Vol 2, pp 1679-1737

38. Lieberman AN, Foo SH, Ranshohoff J, et al: Long term survival among patients with malignant brain tumors. Neurosurgery 10:450-453, 1982

39. Lohne V, Bjornsborg E, Westerby R, et al: Effects of facial paralysis after acoustic neuroma surgery in Norway. J Neurosci Nurs 19:123-131, 1987

40. Lyons GJ: The 'PRESTON Profile'--the first disease-specific tool for assessing quality of life in patients with malignant glioma. Disabil Rehabil 18:460-468, 1996

41. Mackworth N, Fobair P, Prados MD: Quality of life self-reports from 200 brain tumor patients: comparisons with Karnofsky performance scores. J Neurooncol 14:243-253, 1992

42. McDonald ER: Quality of life from the patient's perspective. J Neurosci Nurs 27:222-223, 1995

43. Miller L: The "other" brain injuries: psychotherapeutic issues with stroke and brain tumor patients. Cognit Rehabil 9:10-16, 1991

44. Murray KJ, Nelson DF, Scott C, et al: Quality-adjusted survival analysis of malignant glioma. Patients treated with twice-daily radiation (RT) and carmustine: a report of Radiation Therapy Oncology Group (RTOG) 83-02. Int J Radiat Oncol Biol Phys 31:453-459, 1995

45. Newton C, Mateo MA: Uncertainty: strategies for patients with brain tumor and their family. Cancer Nurs 17:137-140, 1994

46. North CA, North RB, Epstein JA, et al: Low-grade cerebral astrocytomas: Survival and quality of life after radiation therapy. Cancer 66:6-14, 1990

47. Osoba D, Aaronson NK, Muller M, et al: The development and psychometric validation of a brain cancer quality-of-life questionnaire for use in combination with general cancer-specific questionnaires. Qual Life Res 5:139-150, 1996

48. Osoba D, Aaronson NK, Muller M, et al: Effect of neurological dysfunction on health-related quality of life in patients with high-grade glioma. J Neurooncol 34:263-278, 1997

49. Oswin M: The quiet menace. Nurs Times 88:40-41, 1992

50. Parker JDA, Endler NS: Coping with coping assessment: a critical review. Eur J Person 6:321-344, 
51. Patchell RA, Posner JB: Cancer and the nervous system, in Holland JC, Rowland JH (eds):

Handbook of Psychooncology. Psychological Care of the Patient With Cancer. New York: Oxford University Press, 1989

52. Patchell RA, Tibbs PA, Walsh JW, et al: A randomized trial of surgery in the treatment of single metastases of the brain. N Engl J Med 322:494-500, 1990

53. Pilette PC: Conquering a Red Sea experience. J Gerontol Nurs 12:9-13, 1986

54. Sachsenheimer W, Piotrowski W, Bimmler T: Quality of life in patients with intracranial tumors on the basis of Karnofsky's performance status. J Neurooncol 13:177-181, 1992

55. Salander P, Bergenheim T, Henricksson R: The creation of protection and hope in patients with malignant brain tumours. Soc Sci Med 42:985-996, 1996

56. Sarason IG, Johnson JG, Siegel JM: Assessing the impact of life changes, in Sarason IG, Spielberger CD (eds): Stress Anxiety. Washington, DC: 1979, Vol 6, pp 131-149

57. Spiegel D: Health caring. Psychosocial support for patients with cancer. Cancer 74 (Suppl 1):1453-1457, 1994

58. Stewart-Amidei C: Meningioma: nursing care considerations. J Post Anesth Nurs 6:269-278, 1991

59. Taphoorn MJB, Heimans JJ, Snoek FJ, et al: Assessment of quality of life in patients treated for low-grade glioma: a preliminary report. J Neurol Neurosurg Psychiatry 55:372-376, 1992

60. Taphoorn MJB, Heimans JJ, Snoek FJ, et al: Quality of life and neuropsychological functions in long-term low-grade glioma survivors. Int J Radiat Oncol Biol Phys 29:1201-1202, 1994 (Letter)

61. Taphoorn MJB, Schiphorst AK, Snoek FJ, et al: Cognitive functions and quality of life in patients with low-grade gliomas: the impact of radiotherapy. Ann Neurol 36:48-54, 1994

62. Till JE: Measuring quality of life: apparent benefits, potential concerns. Can J Oncol 4:243-248, 1994

63. Tope DM, Ahles TA, Silberfarb PM: Psycho-oncology: psychological well-being as one component of quality of life. Psychother Psychosom 60:129-147, 1993

64. Trojanowski T, Peszynski J, Turowski K, et al: Quality of survival of patients with brain gliomas treated with postoperative CCNU and radiation therapy. J Neurosurg 70:18-23, 1989

65. Visser MRM, Smets EMA: Fatigue, depression and quality of life in cancer patients: how are they related? Support Care Cancer 6:101-108, 1998

66. Weitzner MA, Meyers CA, Byrne K: Psychosocial functioning and quality of life in patients with primary brain tumors. J Neurosurg 84:29-34, 1996

67. Weitzner MA, Meyers CA, Gelke CK, et al: The Functional Assessment of Cancer Therapy (FACT) Scale. Development of a brain subscale and revalidation of the general version (FACT-G) in patients with primary brain tumors. Cancer 75:1151-1161, 1995 
Manuscript received May 27, 1998.

Accepted in final form June 1, 1998.

Address reprint requests to: Terry Bunston, Ph.D., Psychosocial Oncology Program, The Toronto Hospital/Princess Margaret Hospital, 610 University Avenue, Toronto, Ontario, M5G 2M9. email: terry_bunston@pmh.toronto.on.ca. 